\title{
PRODUÇÃO E DECOMPOSIÇÃO DE FITOMASSA DE PLANTAS INVERNAIS DE COBERTURA DE SOLO E MILHO, SOB DIFERENTES MANEJOS DA ADUBAÇÃO NITROGENADA
}

\section{WINTER COVER CROPS AND CORN BIOMASS PRODUCTION AND DECOMPOSITION, UNDER DIFFERENT NITROGEN FERTILIZATION MANAGEMENTS}

\author{
Carlos Alberto Ceretta ${ }^{1}$ Claudir José Basso $^{2}$ Miguel Gustavo Herbes ${ }^{3}$ Naracelis Poletto ${ }^{3}$ \\ Márcio José da Silveira ${ }^{4}$
}

RESUMO

A qualidade do resíduo vegetal e a disponibilidade de nitrogênio $(N)$ mineral são fatores que afetam a decomposição de resíduos vegetais. O presente trabalho teve por objetivo avaliar a produção de matéria seca, o acúmulo de nitrogênio de três plantas para cobertura de solo no inverno e a influência de diferentes épocas de aplicação da adubação nitrogenada na cultura do milho sobre a decomposição do resíduo vegetal mantido na superfície. $O$ experimento foi desenvolvido na Universidade Federal de Santa Maria (RS), nos anos agrícolas de 1996/97 e 1997/98, em solo ARGISSOLO VERMELHO Distrófico arênico (Hapludalf), sendo que a avaliação da taxa de decomposição do resíduo superficial foi feita somente no ano agrícola de 1997/98. O delineamento experimental foi de blocos ao acaso com parcelas subdivididas e três repetições. Nas parcelas principais $(25 \times 5 \mathrm{~m})$, durante o inverno foram utilizadas três coberturas de solo: aveia preta (Avena strigosa Schieb), aveia+ervilhaca (Vicia sativa L.) e nabo forrageiro (Raphanus sativus). Nas subparcelas $\left(5 \times \frac{5}{5}\right)$, diferentes épocas de aplicação de $\mathrm{N}$ no milho: (i)00-00-00, (ii)00-30-90, (iii)30-30-60, (iv)60-30-30 e (v)90-30-00, que corresponde a quantidade de $\mathrm{N} \mathrm{em} \mathrm{kg} \mathrm{ha} a^{-1}$, aplicado em présemeadura (após a dessecação das plantas de cobertura), semeadura, e cobertura do milho (4 a 6 folhas desenroladas). respectivamente. Os resultados mostraram que o cultivo da ervilhaca juntamente com aveia preta não alterou a produção de matéria seca, mas determinou maior teor e acúmulo de nitrogênio na parte aérea das plantas na consorciação. As taxas de decomposição de resíduos de aveia preta, nabo forrageiro e aveia preta+ervilhaca não foram influenciadas pelas épocas de aplicação de nitrogênio para o milho cultivado em sucessão.

Palavras-chave: taxa de decomposição, resíduos culturais, liberação de nitrogênio.

\section{SUMMARY}

The quality of plant residue and soil $N$ availability, from mineral fertilizer, are some of the factors that affect residue decomposition. The objective of this study was to evaluate the dry matter production and its $N$ accumulation in three winter cover crop and the effects of different corn sidedress $N$ timing application on soil surface residue. The experiment was carried out at Federal University of Santa Maria experimental área in $1996 / 97$ and 1997/98 crop season on a typic Hapludalf. The residue decomposition study was carried only in 1997/98 crop season. The experiment was laid out as random block design with split-plot. The main treatments were winter cover crops set up in 25 x 5m plots: a) black oat (Avena strigosa Schieb); b) Black oats+vetch (Vicia sativa L); and c) Raphanus sativus. The splitplot $(5 \times 5 m)$ treatments were splitting and timing $N$ sidedress for corn, which were composed by a sequence of $N$ application, represented by: (1) 00-00-00, (2) 00-30-90, (3) 30-30-60, (4) 6030-30, (5) 90-30-00, where the numbers, respectively, means $N$ applied in $\mathrm{kg} \mathrm{ha}^{-1}$ at: (a) corn pre-planted; (b) at corn seeding; and (c) corn sidedress at 4 to 6 leaves stage. The consortium, black oat+vetch, did not affected dry matter production but induced higher $N$ content and accumulation of above ground biomass. The decomposition rate of winter cover crops was not affected by $N$ sidedress timing for corn in succession of winter cover crops.

Key words: decomposition rate, plant residue, nitrogen release.

\section{INTRODUÇÃO}

A manutenção da palha na superfície do solo é de fundamental importância para a

\footnotetext{
${ }^{1}$ Engenheiro Agrônomo, Professor do Departamento de Solos, Universidade Federal de Santa Maria (UFSM), 97105-900, Santa Maria, RS. Bolsista CNPq. E-mail: ceretta@ccr.ufsm.br . Autor para correspondência.

${ }^{2}$ Doutorando do Programa de Pós-graduação em Agronomia (Biodinâmica do Solo), UFSM.

${ }^{3}$ Estudante de graduação do Curso de Agronomia da UFSM, bolsistas de Iniciação Científica (BIC-FAPERGS e BIC/UFSM/FIPE).

${ }^{4}$ Mestrando do Programa de Pós-graduação em Agronomia, UFSM.
} 
manutenção do sistema plantio direto. Isso reforça a preocupação de produzir resíduos vegetais que tenham decomposição mais lenta, o que significaria manter o resíduo protegendo o solo por maior período de tempo.

Como o sistema plantio direto caracterizase pela manutenção de resíduos culturais e sensível diminuição das perdas de solo por erosão, tem-se observado acréscimos no teor de matéria orgânica no solo (GONÇALVES \& CERETTA, 1999). Isso pode promover alterações no manejo da adubação nitrogenada, embora esta seja influenciada principalmente pela quantidade e características dos resíduos que antecedem, imediatamente, a cultura de interesse.

A taxa de decomposição de resíduos vegetais está associada à relação carbono/nitrogênio $(\mathrm{C} / \mathrm{N})$ do tecido, por isso espécies não gramíneas como ervilhaca e nabo forrageiro possuem maior taxa de decomposição, quando comparadas com gramíneas como aveia preta. O reflexo disso é a intensidade do fenômeno de imobilização de $\mathrm{N}$, que é a principal causa da menor disponibilidade de $\mathrm{N}$ às plantas no sistema plantio direto, em relação ao sistema com revolvimento de solo (SALET $\boldsymbol{e t}$ al., 1997). Entretanto, os níveis de $N$ no solo são determinados não apenas pelo balanço entre a quantidade de $\mathrm{N}$ mineralizada a partir da matéria orgânica, dos resíduos vegetais e da adição através de fertilizantes, mas também pelas perdas de $\mathrm{N}$ por lixiviação, volatilização e denitrificação (CERETTA, 1998).

A aplicação de $\mathrm{N}$ mineral em présemeadura do milho, embora represente uma atitude de risco, promove acréscimos no teor de $\mathrm{N}$ no solo, após o manejo das plantas de cobertura (BASSO \& CERETTA, 2000), o que também poderia influenciar na taxa de decomposição de resíduos vegetais. Isso porque a população e atividade dos microrganismos decompositores é muito influenciada pela quantidade de $\mathrm{N}$ do solo e esse aumento na disponibilidade de $\mathrm{N}$ pode favorecer a taxa de decomposição (WIETHÖLTER, 1996; AITA, 1997), tanto que MARY et al. (1996) observaram que a decomposição de resíduos de plantas em solos com baixas concentrações de $\mathrm{N}$ mineral é diminuída, embora não inibida completamente. Entretanto, FLECHA (2000) não observou incremento na taxa de decomposição de resíduos de aveia preta, quando houve aumento da quantidade de $\mathrm{N}$ no solo.

O objetivo do trabalho foi avaliar a produção de matéria seca e acúmulo de $\mathrm{N}$ em três tipos de cobertura de solo no inverno, bem como o efeito de diferentes épocas de aplicação de $\mathrm{N}$ para o milho, cultivado em sucessão, sobre a decomposição e liberação de $\mathrm{N}$ de resíduos de plantas de cobertura de solo.

\section{MATERIAL E MÉTODO}

O trabalho foi realizado nos anos agrícolas 1996/97 e 1997/98, sob sistema plantio direto, na área experimental do Departamento de Solos da Universidade Federal de Santa Maria, RS, em ARGISSOLO VERMELHO Distrófico arênico (Hapludalf), pertencente à Unidade de Mapeamento São Pedro, com textura franco-arenosa, no horizonte A e franco-argilosa no B. Nos dois anos que antecederam a instalação do experimento, toda a área experimental foi cultivada com aveia preta no inverno e soja no verão, no sistema plantio direto. A produção de matéria seca e acúmulo de $\mathrm{N}$ na parte aérea das plantas de cobertura foi avaliada durante os anos agrícolas 1996/97 e 1997/98, enquanto que a taxa de decomposição e liberação do $\mathrm{N}$ do resíduo mantido na superfície do solo somente foi avaliada no segundo ano agrícola.

O solo amostrado no início do experimento e na profundidade de 0 a $10 \mathrm{~cm}$ apresentou as seguintes características: teor de argila $110 \mathrm{~g} \mathrm{~kg}^{-1} ; \mathrm{pH}$ em $\mathrm{H}_{2} \mathrm{O}$ (1:1) 5,5; índice SMP 6,1; $\mathrm{P}$ $13 \mathrm{mg} \ell^{-1}$; K $58 \mathrm{mg} \ell^{-1}$; M.O. $19 \mathrm{~g} \mathrm{~kg}^{-1}$ de solo; $\mathrm{Ca}^{2+}+$ $\mathrm{Mg}^{2+} 4,7 \mathrm{cmol}_{\mathrm{c}} \ell^{-1}$; e $\mathrm{Al}^{3+}$ zero.

$\mathrm{O}$ delineamento experimental foi de blocos casualizados com parcelas subdivididas e três repetições. Nas parcelas principais de 25 x 5m, durante o inverno, foram implantadas as seguintes coberturas de solo: aveia preta (Avena strigosa Schieb), aveia+ervilhaca (Vicia sativa L.) e nabo forrageiro (Raphanus sativus). Nas subparcelas de 5 x $5 \mathrm{~m}$, foram testadas épocas de aplicação de $\mathrm{N}$ na cultura do milho: a) $00-00-00$; b) $00-30-90$; c) $30-$ 30-60; d) 60-30-30 e e) 90-30-00, cuja sequiência corresponde à quantidade de $\mathrm{N}$ em $\mathrm{kg} \mathrm{ha}^{-1}$ aplicado em pré-semeadura (após o manejo das plantas de cobertura de solo no inverno), semeadura, e cobertura (4 a 6 folhas desenroladas do milho), respectivamente.

$\mathrm{Na}$ semeadura das plantas de cobertura de solo, no inverno, utilizaram-se 100,80 e $15 \mathrm{~kg} \mathrm{ha}^{-1} \mathrm{de}$ semente de aveia preta, ervilhaca e nabo forrageiro, respectivamente. Na consorciação aveia+ervilhaca, foi utilizada uma proporção de 30 e $70 \%$ da densidade de semeadura, ou seja, 30 e $56 \mathrm{~kg} \mathrm{ha}^{-1}$ de semente de aveia preta e ervilhaca, respectivamente.

$\mathrm{Na}$ implantação das plantas de cobertura de solo no inverno, no primeiro ano, aplicaram-se $200 \mathrm{~kg} \mathrm{ha}^{-1}$ da fórmula 5-20-20 e, no segundo ano, 
$40 \mathrm{~kg} \mathrm{ha}^{-1}$ de $\mathrm{P}_{2} \mathrm{O}_{5}$ e $\mathrm{K}_{2} \mathrm{O}$, utilizando-se superfosfato simples e cloreto de potássio, respectivamente e mais $10 \mathrm{~kg} \mathrm{ha}^{-}$ ${ }^{1}$ de $\mathrm{N}$ na forma de uréia. A semeadura das plantas de cobertura e a aplicação de fertilizantes foi a lanço sobre os resíduos vegetais, passando-se posteriormente uma grade leve e sem trava para melhorar o contato das sementes com o solo, evitando-se assim o revolvimento do solo.

No florescimento das plantas de cobertura de solo, foram coletadas amostras da parte aérea para avaliação da produção de matéria seca e acúmulo de $\mathrm{N}$ amostrando-se dois pontos aleatórios de $0,25 \mathrm{~m}^{2}$, dentro de cada parcela principal. O manejo das plantas de cobertura de solo, consistiu da aplicação do dessecante glyfosate, passando-se o rolo faca posteriormente.

A primeira coleta de resíduo vegetal presente na superfície do solo foi realizada antes do manejo das plantas de cobertura de solo. As coletas subsequentes foram feitas em intervalos de 30 dias, a partir da primeira coleta, retirando-se duas subamostras de $0,25 \mathrm{~m}^{2}$ dentro de cada subparcela e na entrelinha do milho cultivado em sucessão.

Os resíduos vegetais foram secos em estufa a $65^{\circ} \mathrm{C}$ até peso constante para determinar a produção de matéria seca. $\mathrm{O}$ teor de $\mathrm{N}$ foi determinado digerindo 0,2 gramas de tecido vegetal com $\mathrm{H}_{2} \mathrm{SO}_{4}$ e mistura de digestão $\left(\mathrm{Na}_{2} \mathrm{SO}_{4}\right.$, $\mathrm{CuSO}_{4} .5 \mathrm{H}_{2} \mathrm{O}$ e selênio) e determinado em destilador de arraste de vapor semi-micro Kjeldahl (TEDESCO et al.,1995).

Os dados referentes à produção de matéria seca e acúmulo de $\mathrm{N}$ na parte aérea das plantas de cobertura de solo foram analisados através da análise da variância e as médias comparadas pelo teste de Duncan a $5 \%$ de probabilidade de erro. Com relação à decomposição e liberação de $\mathrm{N}$, efetuou-se análise da variância, testando a interação de fatores, bem como a análise de regressão.

\section{RESULTADOS E DISCUSSÃO}

A expressiva produção de matéria seca e a quantidade de $\mathrm{N}$ acumulado nas plantas de cobertura de solo no primeiro ano (Tabela 1), deve-se às condições favoráveis do clima mas, principalmente, ao fato de a implantação destas espécies ter sido feita sobre resíduos de soja que havia sido
Tabela 1 - Produção de matéria seca, teor e quantidade de N acumulado pelas plantas de cobertura de solo até o florescimento, nos anos de 1996 e 1997.

\begin{tabular}{|c|c|c|c|c|}
\hline $\begin{array}{c}\text { Plantas de cobertura } \\
\text { De solo }\end{array}$ & $\begin{array}{l}\text { Matéria } \\
\text { seca }\end{array}$ & $\begin{array}{l}\text { Teor de } \\
\text { nitrogênio }\end{array}$ & $\begin{array}{l}\text { Nitrogênio } \\
\text { acumulado }\end{array}$ & $\begin{array}{c}\text { Relação } \\
C: N^{(3)}\end{array}$ \\
\hline & \multicolumn{4}{|c|}{ 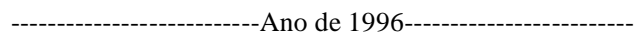 } \\
\hline & $\mathrm{Mg} \mathrm{ha}^{-1}$ & $\mathrm{~g} \mathrm{~kg}^{-1}$ matéria seca & $\mathrm{kg} \mathrm{ha}^{-1}$ & \\
\hline Aveia preta & $7,36 \mathrm{a}^{(2)}$ & $10,82 \mathrm{c}$ & $80 \mathrm{~b}$ & 37 \\
\hline Aveia preta+ervilhaca & $6,11 \mathrm{a}$ & $17,57 \mathrm{a}$ & $107 \mathrm{a}$ & 23 \\
\hline Nabo forrageiro & $5,16 \mathrm{~b}$ & $14,16 \mathrm{~b}$ & $73 \mathrm{~b}$ & 28 \\
\hline & \multicolumn{4}{|c|}{ 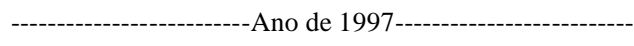 } \\
\hline Aveia preta & $4,05 \mathrm{ab}$ & $10,70 \mathrm{c}$ & $43 \mathrm{~b}$ & 38 \\
\hline Aveia preta+ervilhaca & $4,61 \mathrm{a}$ & $21,60 \mathrm{a}$ & $100 \mathrm{a}$ & 18 \\
\hline Nabo forrageiro & $3,40 \mathrm{~b}$ & $13,10 \mathrm{~b}$ & $45 \mathrm{~b}$ & 30 \\
\hline
\end{tabular}

${ }^{(1)}$ Plantas de cobertura de solo utilizadas como cultivo invernal

(2) Médias seguidas da mesma letra não diferem pelo teste de Duncan a $5 \%$ de probabilidade de erro.

${ }^{(3)}$ Considerando que $40 \%$ da matéria seca total é carbono.

Os coeficientes de variação em 1996 foram de 16,1, 10,1 e 15,4\% e, em 1997, foram de $8,8,4,5$ e 7,6\%, para matéria seca, teor de nitrogênio e nitrogênio acumulado na parte aérea, respectivamente.

cultivada anteriormente na área. O cultivo anterior de soja pode significar a contribuição de 17 a $59 \mathrm{~kg}$ ha $^{-1}$ de N para culturas em sucessão, como foi o caso do trigo, citado por WIETHÖLTER (1996).

$\mathrm{Na}$ consorciação aveia preta+ervilhaca, observou-se um aspecto importante do ponto de vista de rotação de plantas de cobertura de solo. Houve variação na contribuição relativa de cada espécie na produção de matéria seca nos dois anos (Figura 1). Observa-se que, em 1996, quando aveia preta+ervilhaca foram cultivadas sobre resíduos de

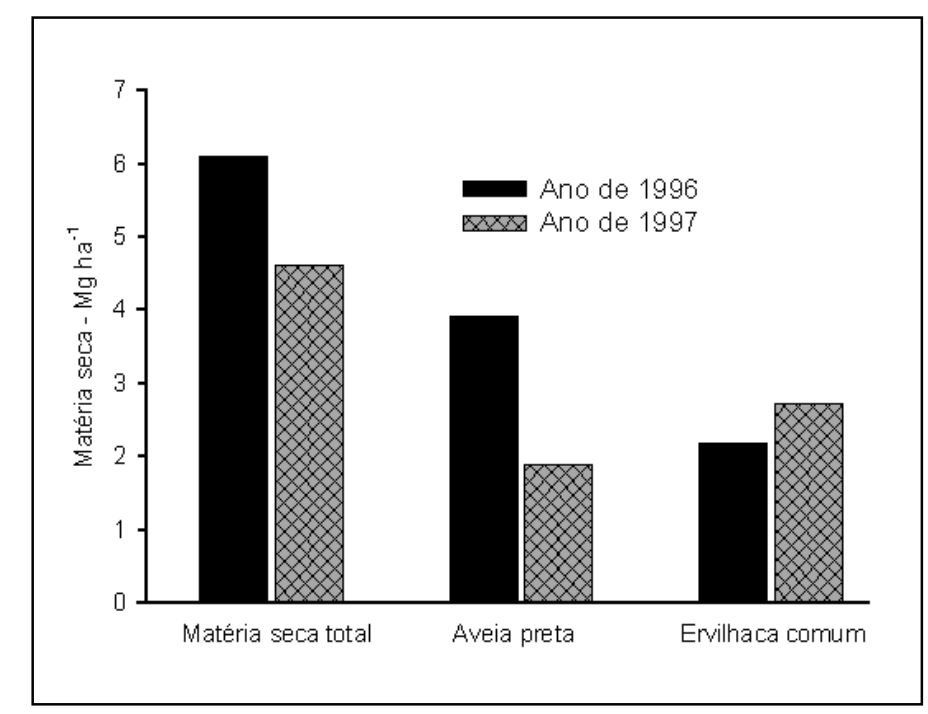

Figura 1 - Proporção de matéria seca de aveia preta e de ervilhaca comum na consorciação nos anos de 1996 e 1997 . Média de 3 repetições.

Ciência Rural, v. 32, n. 1, 2002. 
soja houve maior participação da aveia preta na produção de matéria seca, ao contrário do que ocorreu em 1997, quando a consorciação foi estabelecida sobre resíduos de milho. Isso fica evidente quando se observa que, na consorciação, a proporção de aveia preta e de ervilhaca sobre a produção total de matéria seca foi de 64 e $36 \%$ e 41 e $59 \%$ para os anos de 1996 e 1997 . Isso mostra que sob uma condição onde ocorre um acúmulo de resíduo com relação $\mathrm{C} / \mathrm{N}$ alta, tenderá a ocorrer uma redução na disponibilidade de N. Nesse caso, a leguminosa terá maior poder de competição com a gramínea, devido a capacidade desta em suprir parte ou totalmente sua necessidade de $\mathrm{N}$ através da fixação simbiótica. Essa é uma provável explicação para a maior produção de matéria seca da aveia preta nesse trabalho em comparação com o realizado por DA ROS et al., (1996), que trabalharam em condições semelhantes de clima e solo e cultivaram aveia preta em sucessão a milho.

A presença da ervilhaca como leguminosa na consorciação com aveia preta deve ser a principal justificativa para o maior teor e quantidade de $\mathrm{N}$ acumulado na matéria seca da parte aérea nos dois anos, o que favoreceu a uma relação $\mathrm{C} / \mathrm{N}$ menor. Isso mostra a importância da presença da ervilhaca na consorciação com aveia preta, quando o objetivo é também utilizar plantas de cobertura do solo para aumento de $\mathrm{N}$ no solo e suas conseqüências benéficas à nutrição de plantas em sucessão, especialmente gramíneas. Entretanto, essa contribuição da ervilhaca no aporte de $\mathrm{N}$ para o solo depende de sua densidade em relação à aveia preta e isso ficou demonstrado nas várias combinações feitas por HENRICHS (1996).

A avaliação da decomposição dos resíduos das plantas de cobertura mostrou que, aos 30 dias após a dessecação os porcentuais foram de $38 \%$ para o nabo forrageiro e aveia+ervilhaca e $34 \%$ para a aveia preta, enquanto que aos 120 dias os porcentuais foram de 72 , 67 e $66 \%$ para os resíduos de nabo forrageiro, aveia+ervilhaca e aveia preta, respectivamente (Figura 2).

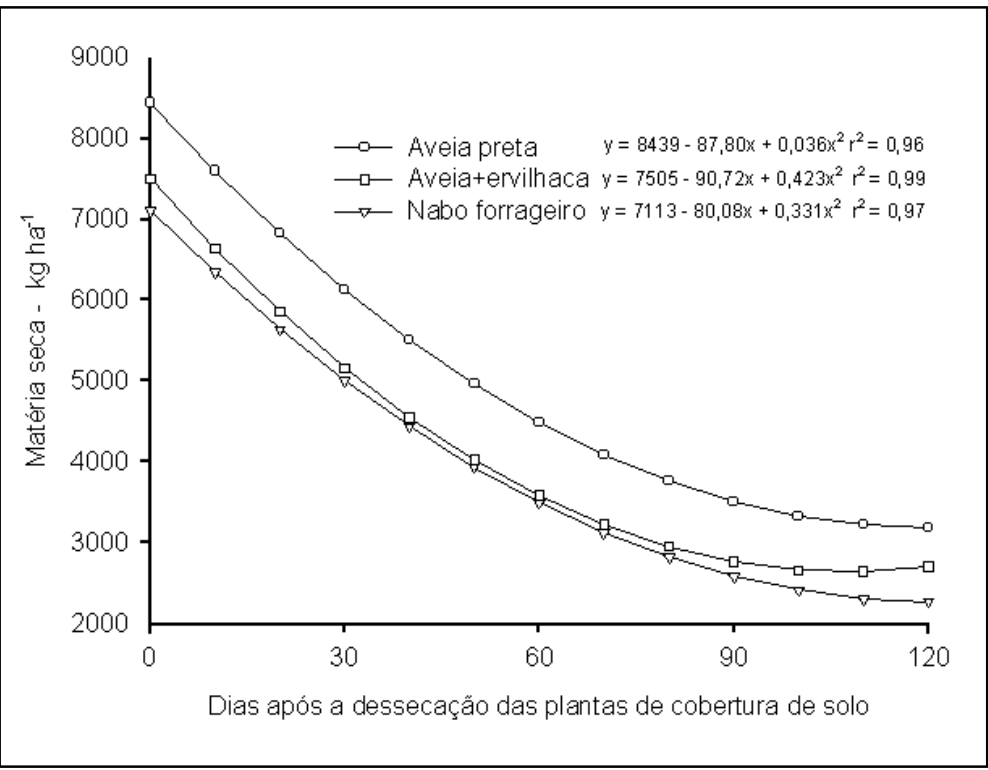

Figura 2 - Decomposição de resíduos de plantas de cobertura de solo no ano agrícola $1997 / 98$.

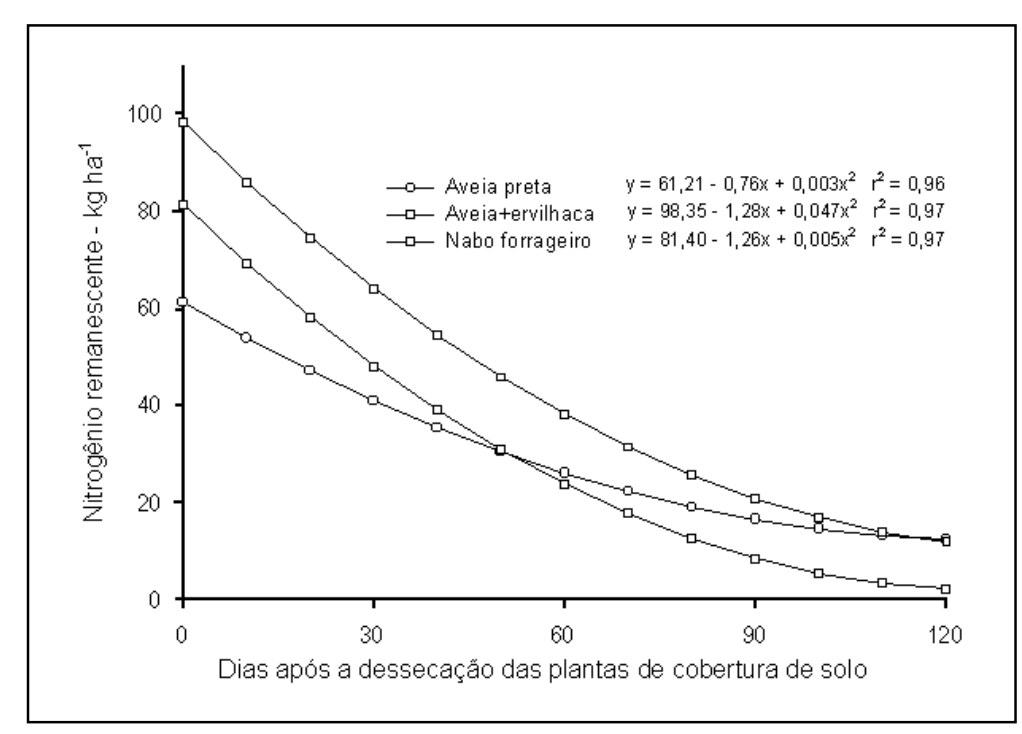

Figura 3 - Liberação de nitrogênio de resíduos de plantas de cobertura de solo no ano agrícola 1997/98.
A quantidade de $\mathrm{N}$ liberado do resíduo
também foi mais expressiva nos primeiros 30 dias após a dessecação das plantas de cobertura atingindo porcentuais de 50, 44 e $42 \%$ no caso do nabo forrageiro, aveia+ervilhaca e aveia preta, respectivamente. Aos 120 dias após o manejo, a liberação de $\mathrm{N}$ atingiu 94, 91 e $85 \%$ para o nabo forrageiro, aveia+ervilhaca e aveia preta, respectivamente (Figura 3). Trabalho realizado durante dois anos na mesma área experimental usando aveia preta como cobertura de solo também 
mostrou porcentuais médios de decomposição de 59 e $83 \%$ aos 30 e 120 dias após a dessecação da aveia preta (DA ROS, 1993). A elevada decomposição e liberação de $\mathrm{N}$ no período inicial, mostra que, para maximizar o aproveitamento desse nutriente, a implantação da cultura econômica deverá ser feita o quanto antes após o manejo dessas plantas de cobertura, conforme sugere HEINZMANN (1985).

$\mathrm{O}$ aumento na disponibilidade de $\mathrm{N}$ no solo proporcionado pela aplicação de fertilizante nitrogenado mineral em diferentes épocas e visando a cultura do milho em sucessão às plantas de cobertura do solo foi demonstrado por BASSO \& CERETTA (2000), mas isso não afetou a taxa de decomposição dos resíduos das plantas de cobertura (Figura 4), à semelhança do que obteve DIEKOW (2000), quando avaliou a decomposição de aveia preta aplicando $\mathrm{N}$ em várias épocas para o milho em sucessão. Esses resultados contrariam expectativas feitas a partir de informações de AITA, (1997) e MARY et al. (1996) e mesmo de WIETHÖLTER (1996) que, após adicionar N na superfície do solo por ocasião da semeadura do trigo, verificou um pequeno incremento na decomposição do resíduo de milho. Contudo, deve ser considerado que após a dessecação das plantas de cobertura do solo e durante o cultivo do milho em sucessão em 1997 ocorreram precipitações pluviométricas muito acima das normais, devido ao fenômeno "El Niño", que está bem demonstrado em BASSO \& CERETTA (2000) e que causou intensa lixiviação de N no solo.

\section{CONCLUSÕES}

O cultivo da ervilhaca consorciada com aveia preta não alterou a produção de matéria seca, em relação aos cultivos solteiros mas mostrou que é uma boa estratégia especialmente para aumentar o aporte de $\mathrm{N}$ no solo.

As taxas de decomposição de resíduos de aveia preta, nabo forrageiro e aveia preta+ervilhaca não foram influenciadas pelas épocas de aplicação de nitrogênio para o milho cultivado em sucessão.

\section{REFERÊNCIAS BIBLIOGRÁFICAS}

AITA, C. Atualização em Adubação e calagem: ênfase em plantio direto. Santa Maria, RS : UFSM/Departamento de Solos, 1997. Dinâmica do nitrogênio no solo durante a decomposição de plantas de cobertura e efeito sobre a disponibilidade de nitrogênio para a cultura em sucessão: p.76-111.

BASSO, C.J.; CERETTA, C.A. Manejo do nitrogênio no milho em sucessão a plantas de cobertura de solo, sob plantio direto. R Bras Ci Solo, Viçosa, v.24, n.4, p.905-915, 2000.

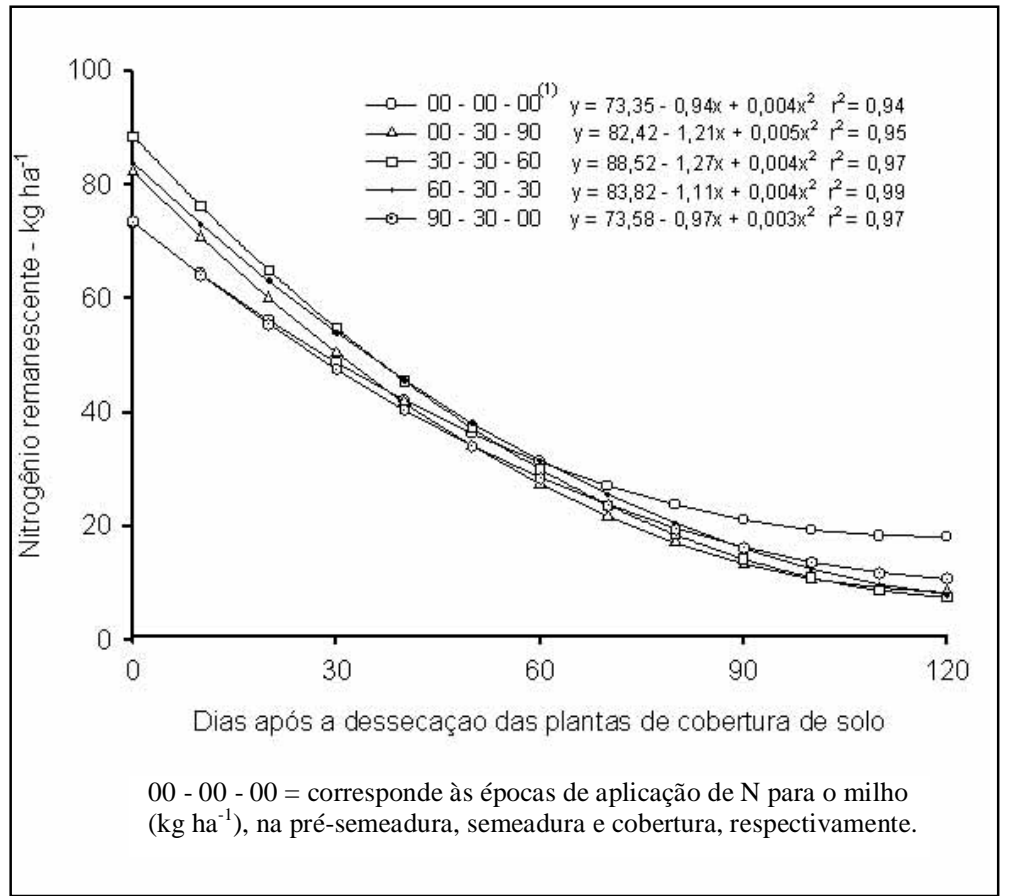

Figura 4 - Liberação de nitrogênio de resíduos superficiais sob diferentes épocas de aplicação de N no milho, no ano agrícola 1997/98.
CERETTA, C.A. Adubação nitrogenada no sistema plantio direto:sucessão aveia/milho. In: CONFERÊNCIA ANUAL DE PLANTIO DIRETO, $2 . \quad$ Ijuí, RS. Anais... Passo Fundo, RS, Editora Aldeia Norte, 1998, p.49-62.

DA ROS, C.O. Plantas de inverno para cobertura do solo e fornecimento de nitrogênio ao milho em plantio direto. Santa Maria, 1993. 85p. Dissertação (Mestrado em Agronomia) - Programa de Pós-graduação em Agronomia, Universidade Federal de Santa Maria, 1993.

DA ROS, C.O.; AITA, C. Efeito de espécies de inverno na cobertura do solo e fornecimento de nitrogênio ao milho em plantio direto. $\mathbf{R}$ bras Ci Solo, Campinas, v.20, n.1, p.135140, 1996.

DIEKOW, J. Antecipação da adubação nitrogenada em milho cultivado no sistema plantio direto, em sucessão à aveia preta. Porto Alegre, 2000. 74p. Dissertação (Mestrado em Ciência do Solo) Programa de Pós-graduação em Agronomia, Universidade Federal do Rio Grande do Sul. 2000.

FLECHA, A.M.T. Possibilidade de manejo da adubação nitrogenada na cultura do milho, em sucessão a aveia preta no 
sistema plantio direto. Santa Maria, 2000. 37p. Dissertação (Mestrado em Agronomia) - Programa de Pósgraduação em Agronomia, Universidade Federal de Santa Maria, 2000.

GONÇALVES, C.N.; CERETTA, C.A. Plantas de cobertura de solo antecedendo o milho e seu efeito sobre o carbono orgânico do solo, sob plantio direto. R bras Ci Solo, Viçosa, v.23, p.307-313, 1999.

HENRICHS, R. Ervilhaca e aveia preta cultivadas simultaneamente como adubo verde e sua influência no rendimento do milho. Piracicaba, 1996. 65p. Dissertação (Mestrado em Agronomia) Curso de Pós-graduação em Agronomia, Escola Superior de Agricultura Luiz de Queiroz, 1996.

HEINZMANN, F.X. Resíduos culturais de inverno e assimilação de nitrogênio por culturas de inverno. Pesq Agropec Bras, Brasília, v.20, n.9, p.1021-1030, 1985.
MARY, B.; RECOUS, S.; DARWIS, D., ROBIN, D. Interactions between decomposition of plant residues and nitrogen cycling in soil. Plant and Soil, The Hague, v.181, n.1, p.71-82, 1996.

SALET, R.L.; VARGAS, L.K.; ANGHINONI, et al. Porque a disponibilidade de nitrogênio é menor no sistema plantio direto? In: SEMINÁRIO INTERNACIONAL DO SISTEMA PLANTIO DIRETO, 2, 1997, Passo Fundo, RS. Anais.... Passo Fundo, RS : Aldeira Norte, 1997. p.217.

TEDESCO, M.J.; GIANELLO, C.; BISSANI, C.A., et al. Análise de solo, plantas e outros materiais. Porto Alegre : Departamento de Solos, UFRGS, 1995. 174p.

WIETHÖLTER, S. Adubação nitrogenada no sistema plantio direto. Passo Fundo : EMBRAPA-CNPT, 1996. 44p. 